\title{
The impact of chronic pain on direct medical utilization and costs in chronic obstructive pulmonary disease
}

This article was published in the following Dove Press journal:

ClinicoEconomics and Outcomes Research

26 March 2015

Number of times this article has been viewed

\author{
Melissa H Roberts' \\ Douglas W Mapel' \\ Heather N Thomson ${ }^{2}$ \\ 'Lovelace Clinic Foundation, \\ Albuquerque, NM, USA; ${ }^{2}$ Endo \\ Pharmaceuticals, Malvern, PA, USA
}

Correspondence: Douglas W Mapel Lovelace Clinic Foundation, 2309 Renard Place SE, Suite 103, Albuquerque, NM 87I06, USA

Tel +l 505235 I434

Fax + I 5059389940

Email dmapel@comcast.net
Objective: To examine how pain affects health care utilization and direct medical costs in individuals with chronic obstructive pulmonary disease (COPD) compared to patients with other chronic diseases.

Study design: A retrospective cohort analysis using administrative data of a managed health care system in the Southwestern US for years 2006-2010.

Methods: COPD patients age $\geq 40$ years were matched to similar patients with other chronic conditions on age, sex, insurance type, and a health care event (outpatient visit, emergency department visit, or inpatient stay). Chronic pain was indicated by pain-associated diagnoses and procedures, or fills for prescription pain medications. The study population was also stratified into those with and without chronic pain to examine clinical factors and costs associated with chronic pain.

Results: Seven thousand nine hundred and fifty-two COPD patients (mean age 69 years, $58 \%$ women) were matched to 15,904 patients with other chronic disease. COPD patients had significantly higher utilization for pain-related services and for overall services. COPD patients had a higher prevalence of any pain medication use over a 12 -month period $(41.2 \%$ versus $31.5 \%)$ and, among those using pain medications, a higher mean number of pain medication prescription fills (10.1 versus 6.4). Factors associated with chronic pain included age 40-65 years, being female, having more than one chronic morbidity, insurance type, some emergency department or hospital utilization, and having either COPD, heart failure, arthritis, or stroke. Among COPD patients, those with chronic pain had a mean annual direct cost for overall utilization of $\$ 24,261$ versus $\$ 10,390$ among those without chronic pain $(P<0.0001$ for all comparisons).

Conclusion: COPD patients have substantially more utilization for pain medications and pain-related procedures than those with most other chronic diseases. Total direct medical costs among COPD patients who have chronic pain are more than double those of COPD patients without chronic pain. Pain management may be an opportunity for better and more cost-effective care for COPD patients.

Keywords: chronic disease, cost of illness, comorbidity, opioids

\section{Introduction}

Chronic obstructive pulmonary disease (COPD) is the variable combination of emphysema and chronic bronchitis. These chronic conditions are usually found in adults $\geq 40$ years of age and are caused by inflammatory responses to cigarette smoke and other inhaled noxious particulates, and result in persistent expiratory airflow limitation and chronic respiratory symptoms such as shortness of breath, cough, and wheezing. ${ }^{1}$ The World Health Organization estimates that more than 3 million persons 
die from COPD every year, which is approximately $5 \%$ of all deaths globally, and the prevalence of COPD is increasing worldwide. ${ }^{2}$ In the US, COPD has surpassed stroke to become the third most common cause of death, and data extrapolated from surveys estimate that over 24 million persons in the US are currently affected by COPD..$^{2-5}$ COPD is now a leading cause of work disability in most industrial nations, and the demographics of COPD are changing such that more working-age adults will be affected. ${ }^{6-9}$

The high prevalence and substantial morbidity associated with COPD result in very high and growing societal and health care costs for this disease. Chronic respiratory diseases including COPD are among the top five reasons for outpatient clinic and emergency department visits in the US, ${ }^{10}$ and are also among the top ten costliest chronic conditions. ${ }^{11}$ These conditions are also the fourth leading cause of medical disability among adults in the US, ${ }^{12}$ and result in over US\$6.35 billion of lost productivity each year. ${ }^{13}$ Direct and indirect cost estimates from other industrialized countries vary widely but consistently demonstrate that COPD is among the most expensive chronic illnesses and causes of disability. ${ }^{14}$

A large part of the increased health care utilization found among COPD patients is attributable to the high prevalence of comorbidities, especially other diseases associated with cigarette smoking, such as lung cancer and cardiovascular diseases. ${ }^{15,16}$ In an analysis of the Chronic Conditions Data Warehouse, which comprises US Medicare recipient data, $71.7 \%$ of COPD patients had one or more other major chronic conditions, as compared to $52.8 \%$ of diabetes patients and $55.7 \%$ of cancer patients. ${ }^{17}$ In a recent analysis of chronic pain among COPD patients in this system, we found that COPD patients had a substantially higher prevalence of chronic pain than those with any other chronic disease except osteo- and/or rheumatoid arthritis (OA/RA), and use of short- and long-acting opioids among COPD patients was even greater than that seen in OA/RA. ${ }^{18}$

Although the available research suggests an increased prevalence of pain among persons with COPD, ${ }^{19-22}$ it is not known how this affects health care utilization and costs, or whether the impact of pain on health care utilization among those with COPD is any greater than that seen among patients with other chronic diseases. The main objective of this project is to compare direct health care utilization and costs for pain management in individuals with COPD to a matched population of patients with other chronic diseases. Secondary objectives are to compare, in the overall matched population, health care cost and utilization between patients with and without chronic pain to identify clinical factors associated with increased pain prevalence; and to compare medical costs among COPD patients with and without chronic pain. This analysis is an extension of the work we have published on the basic epidemiology of chronic pain in a populationbased COPD cohort. $^{18}$

\section{Methods}

The study population was selected from adult members (age $\geq 40$ years of age) of a regional health insurance provider based in Albuquerque, NM, USA that covers approximately 220,000 persons annually. The time period for the analysis is January 1, 2006 through December 31, 2010. Ethical and Independent Review Services provided institutional review board approval (\#11284-01).

Details of the cohort selection process and the process for identifying chronic pain events are described elsewhere, ${ }^{18}$ but are summarized briefly here. Evidence of pain is shown by an encounter (inpatient, outpatient, or emergency department [ED] visit) with a pain-related International Classification of Diseases, Ninth Revision, Clinical Modification (ICD-9-CM) diagnosis code, receipt of a procedure-based pain therapy, or an outpatient prescription claim for pain medication. Patients with COPD were individuals with an ICD-9-CM diagnosis code of 491.x, 492.x, or 496. Patients without COPD had at least one of the following Centers for Medicare and Medicaid Services (CMS) Chronic Conditions Data Warehouse-defined conditions: Alzheimer's and related disorders, atrial fibrillation, cancers (colorectal, endometrial, female breast, lung, and/or prostate), chronic kidney disease, diabetes, heart failure, ischemic heart disease, osteo- and/or rheumatoid arthritis (OA/RA), or stroke/transient ischemic attack. ${ }^{23}$ Included patients had to have at least one inpatient diagnosis or two outpatient visit diagnoses (to include ED visits) for COPD or one of the other chronic conditions. The presence of other morbidities was identified using the Elixhauser classification system. ${ }^{24}$ The analysis period consisted of 15 months, 3 months of which was prior to the matching event, and 12 months post-matching event. Individuals were required to have continuous health plan enrollment over the 15-month analysis period. Morbidities for individuals were identified in the analysis period.

For the matched analysis, each individual with COPD was matched to two individuals without COPD but with another chronic disease. Patients with COPD were matched with patients without COPD but with another chronic condition based on a similar type of health care event in order to minimize selection bias due to types of 
health care utilization (eg, to avoid matching someone with an inpatient stay with someone who has never been hospitalized). Matching was based on the following factors: age at matching event ( \pm 2 years), sex, type of matching event (inpatient, outpatient, or ED visit), type of insurance coverage on the matching event date, and matching event date ( \pm 6 months).

Chronic pain was defined as repeated utilization for the same pain-related diagnosis or procedure, or a repeated pain medication prescription fill, occurring within a specified time period. The second pain event was considered the initial date of chronic pain. Chronic pain events within each of the three areas (diagnoses, procedures, pharmacy) were tracked for continuity. If repeated events occurred in less than 30 days, they were considered a continuation of the same acute event. If more than 60 days transpired between events, then they were considered separate acute pain events. The system for identifying pain-related procedures and drugs is described in an earlier publication. ${ }^{18}$

Direct costs in this analysis are from the perspective of the payer and represent amounts paid by the managed care plan. They do not include co-pay amounts. All costs were adjusted on a monthly basis to December 2010 using the US Medical Care Consumer Price Index. Costs were stratified as either inpatient (hospitalizations and institutional stays), ambulatory (outpatient, ED - not admitted, laboratory, and outpatient procedures), or outpatient pharmacy claims.

\section{Statistical methods}

All categorical variables were compared using chi-square statistics. Normally distributed means were compared using the Student's $t$-test, and nonparametric continuous data were compared using the Wilcoxon rank-sum test. McNemar's test was used for the matched comparisons. Effect sizes were estimated using absolute standardized differences. Effect size estimates are calculated independent of sample size and provide a measure of average difference expressed in standard deviation units. For continuous variables the effect size was the absolute value of the difference between two sample means divided by the square root of one-half of the sum of the two sample variances. For categorical variables it was the difference between two sample percentages divided by the square root of one-half of the sum of sample percentage $\# 1 \times(1$-sample percentage $\# 1)$ and sample percentage \#2 $\times(1$-sample percentage \#2). Traditionally, effect sizes of approximately $0.2,0.5$, and 0.8 have been considered small, medium, and large effect sizes, respectively, and effect sizes of 0.10 or smaller have not been considered as important. ${ }^{25}$ All data processing, matching of patients, and statistical analyses were conducted using SAS $^{\circledR}$ software.

\section{Results}

There were 8,678 patients with COPD and 25,390 patients without COPD but with another chronic disease that were identified as eligible for the study. The matched population comprised 7,952 COPD patients and 15,904 patients with other chronic disease (Table 1). More than half of the matched patients were women (58\%). Most patients were covered by public health insurance (51.9\% Medicare, $8.4 \%$ Medicaid). The overwhelming majority of matching events (93.1\%) were outpatient visits. The mean age of patients with COPD was 69.3 years, slightly older ( 0.9 years) than those without (effect size 0.08). A lower percentage of patients with COPD were of Hispanic ethnicity compared to patients without COPD, which is consistent with other surveys in this region of the US (effect size 0.28). ${ }^{26,27}$

Among patients with COPD, $78.4 \%$ had more than one chronic condition, compared to $47.3 \%$ of patients without COPD (effect size 0.68); these percentages are similar to those observed for US Medicare patients. ${ }^{17}$ COPD patients had substantially more cardiovascular complications, while patients without COPD were more likely to have diabetes and OA/RA (Table 1). Table 2 provides prevalence estimates of Elixhauser morbidities for patients without COPD, overall and stratified by chronic condition, in comparison to patients with COPD. Those with COPD had a lower prevalence of uncomplicated diabetes, but significantly higher prevalence of almost every other comorbidity.

Patients with COPD had significantly higher all-cause utilization in almost every service area, both in terms of the proportion in the cohort needing the service and the mean events per patient (Table 3 ). Evidence of chronic pain was identified based on repeated pain-related diagnoses, procedures, or medications. Figure 1 provides information on the percentages of COPD and non-COPD patients identified to have evidence of chronic pain across all areas, and then for just pain-related procedures (Figure 1B), painrelated medications (Figure $1 \mathrm{C}$ ), and, within pain-related medications, short- and long-acting opioids (Figure 1D). In addition to evidence of chronic pain, pain-related utilization was substantially higher for patients with COPD (Table 3). Patients with COPD had higher pain-related utilization for inpatient, outpatient, and pharmacy services than patients without COPD, except for those with OA/ RA. Although patients without COPD who had OA/RA 
had a higher proportion using pain-related ambulatory services, patients with COPD had a substantially higher proportion with pain-related inpatient visits and outpatient prescription fills.

The COPD and non-COPD matched groups were restratified into patients with and without evidence of chronic pain to identify factors associated with health care utilization for chronic pain (Table 4). Persons below age 65 years were more likely to have chronic pain utilization than those 65 years and older, in particular those aged 40 to 54 years ( $16.6 \%$ versus $10.4 \%$; effect size 0.18 ). Women were more likely to have chronic pain utilization than men $(64.2 \%$ versus $50.6 \%$; effect size 0.28 ). Hispanic ethnicity did not have a substantial association with pain utilization. A greater percentage of persons with Medicaid as their primary insurance were among those with chronic pain $(11.9 \%$ versus $4.2 \%$; effect size 0.29). Among chronic conditions, OA/RA was most strongly associated with chronic pain utilization (effect size 0.60), followed by COPD (effect size 0.15). Heart failure, stroke/transient ischemic attack, chronic kidney disease, and diabetes were also significantly associated with chronic pain utilization, but had effect sizes less than or equal to 0.10 .

Table 5 provides a comparison of all-cause and painrelated utilization between patients with and without evidence of chronic pain. Patients with chronic pain had significantly higher utilization in all categories, and their all-cause ED visits and inpatient stays are approximately double those without chronic pain. However, pain-related utilization does not fully account for the difference in

Table I COPD and matched non-COPD patients: demographic characteristics, matching factors, and chronic morbidity prevalence

\begin{tabular}{|c|c|c|c|c|c|c|}
\hline & \multicolumn{2}{|c|}{$\begin{array}{l}\text { COPD } \\
(n=7,952)\end{array}$} & \multicolumn{2}{|c|}{$\begin{array}{l}\text { Non-COPD } \\
(n=15,904)\end{array}$} & \multirow[t]{2}{*}{$P$} & \multirow[t]{2}{*}{$\begin{array}{l}\text { Effect } \\
\text { size }\end{array}$} \\
\hline & $\mathbf{N}$ & $\%$ & $\mathbf{N}$ & $\%$ & & \\
\hline \multicolumn{7}{|l|}{ Age categories ${ }^{\mathrm{a}}$} \\
\hline $40-54$ years & 1,028 & $(12.9)$ & 2,257 & $(14.2)$ & 0.008 & 0.04 \\
\hline $55-64$ years & $\mathrm{I}, 464$ & $(18.4)$ & 2,945 & $(18.5)$ & 0.84 & 0.00 \\
\hline $65-74$ years & 2,604 & $(32.7)$ & 5,625 & $(35.4)$ & $<0.0001$ & 0.06 \\
\hline$\geq 75$ years & 2,856 & $(35.9)$ & 5,077 & $(31.9)$ & $<0.0001$ & 0.08 \\
\hline Age (years), mean (SD) & 69.3 & $(11.7)$ & 68.4 & $(11.6)$ & $<0.0001$ & 0.08 \\
\hline Female $^{\mathrm{a}}$ & 4,609 & $(58.0)$ & 9,218 & $(58.0)$ & 1.00 & 0.00 \\
\hline Hispanic ethnicity & 2,225 & $(28.0)$ & 6,570 & $(4 I .3)$ & $<0.0001$ & 0.28 \\
\hline \multicolumn{7}{|l|}{ Insurance coverage at matching event ${ }^{\mathrm{a}}$} \\
\hline Commercial & 3,205 & $(40.3)$ & 6,410 & $(40.3)$ & 1.00 & 0.00 \\
\hline Medicaid & 665 & (8.4) & 1,330 & (8.4) & 1.00 & 0.00 \\
\hline Medicare & 4,125 & $(51.9)$ & 8,250 & $(51.9)$ & 1.00 & 0.00 \\
\hline \multicolumn{7}{|l|}{ Type of encounter for matching ${ }^{a}$} \\
\hline Ambulatory visit & 7,401 & $(93.1)$ & 14,802 & $(93.1)$ & 1.00 & 0.00 \\
\hline ED visit & 352 & $(4.4)$ & 704 & $(4.4)$ & 1.00 & 0.00 \\
\hline Discharge from inpatient stay & 199 & $(2.5)$ & 398 & $(2.5)$ & 1.00 & 0.00 \\
\hline \multicolumn{7}{|l|}{ Chronic conditions ${ }^{\mathrm{b}}$} \\
\hline AMI & 474 & $(6.0)$ & 533 & (3.4) & $<0.0001$ & 0.12 \\
\hline $\begin{array}{l}\text { Alzheimer's, related disorders, or } \\
\text { senile dementia }\end{array}$ & 711 & $(8.9)$ & 1,289 & $(8.1)$ & 0.03 & 0.03 \\
\hline Atrial fibrillation & 1,228 & $(15.4)$ & I,325 & $(8.3)$ & $<0.0001$ & 0.22 \\
\hline Cancers $^{c}$ & 942 & $(I 1.8)$ & $|, 84|$ & $(I 1.6)$ & 0.54 & 0.01 \\
\hline COPD & 7,952 & $(100)$ & - & - & & \\
\hline CKD & 2,429 & $(30.5)$ & 4,584 & $(28.8)$ & 0.006 & 0.04 \\
\hline Diabetes & 2,289 & $(28.8)$ & 6,594 & $(4 I .5)$ & $<0.0001$ & 0.27 \\
\hline Heart failure & 2,186 & $(27.5)$ & 1,694 & $(10.7)$ & $<0.0001$ & 0.44 \\
\hline Ischemic heart disease & 2,528 & $(31.8)$ & 3,472 & $(21.8)$ & $<0.0001$ & 0.23 \\
\hline OA/RA & 2,463 & $(31.0)$ & 6,439 & $(40.5)$ & $<0.0001$ & 0.20 \\
\hline Stroke/transient ischemic attack & 992 & $(12.5)$ & 1,616 & $(10.2)$ & $<0.0001$ & 0.07 \\
\hline Individuals with $>$ I chronic condition & 6,238 & $(78.4)$ & 7,530 & $(47.3)$ & $<0.0001$ & 0.68 \\
\hline
\end{tabular}

Notes: ${ }^{a}$ Factor on which patients were matched (age matching was \pm 2 years); bbased on one inpatient or two outpatient (ambulatory or ED visit) International Classification of Diseases, Ninth Revision, Clinical Modifiation diagnosis codes listed in Centers for Medicare and Medicaid Services Chronic Conditions Data Warehouse definitions; 'included cancer diagnoses: colorectal, endometrial, female breast, lung, or prostate.

Abbreviations: AMI, acute myocardial infarction; CKD, chronic kidney disease; COPD, chronic obstructive pulmonary disease; ED, emergency department; OA/RA, osteoand/or rheumatoid arthritis; SD, standard deviation. 


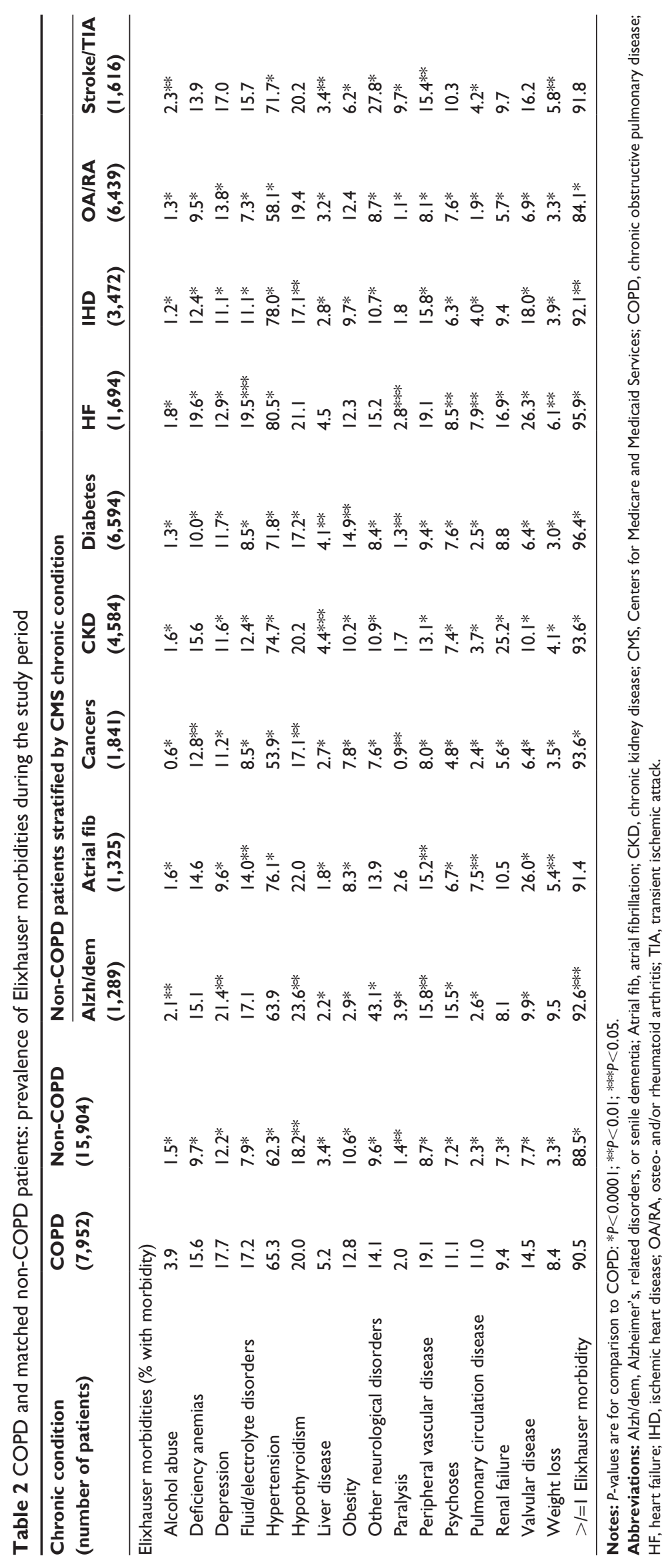




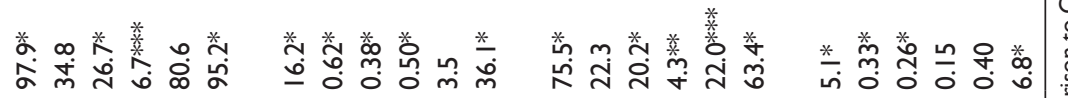

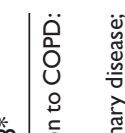

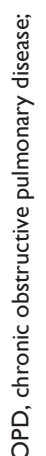

全

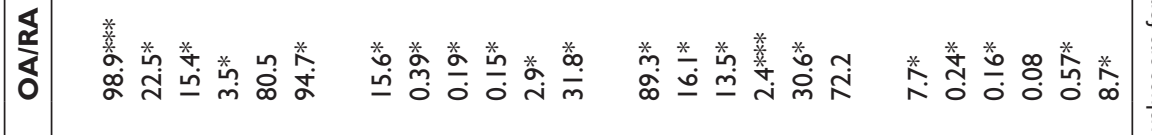

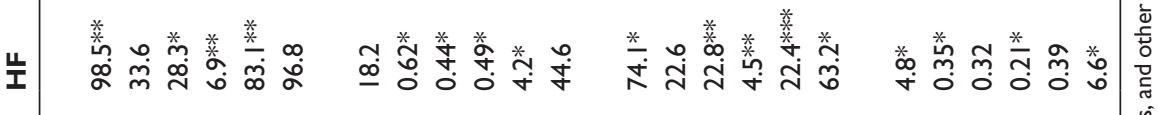

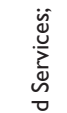

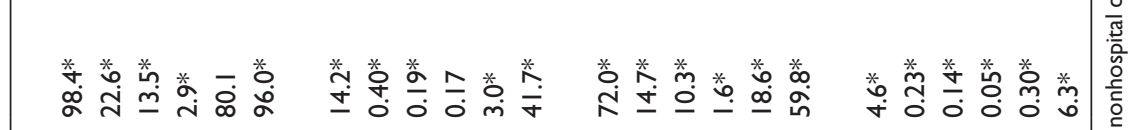

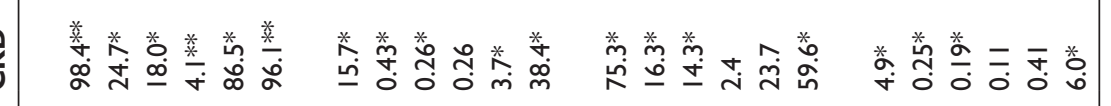

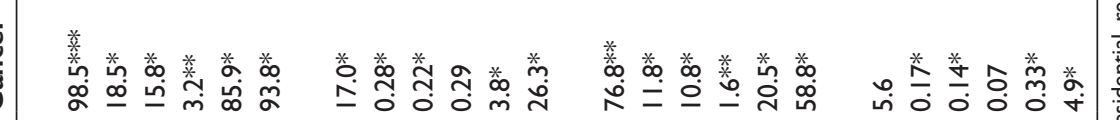

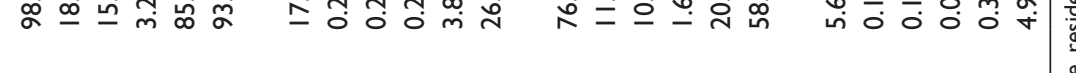

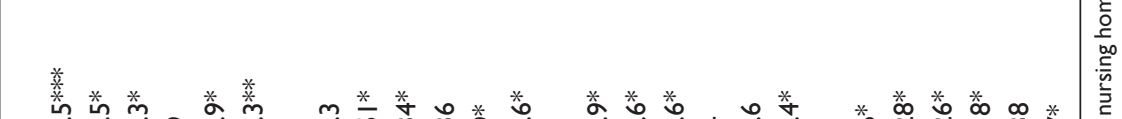

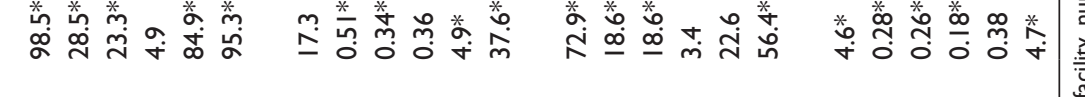


A

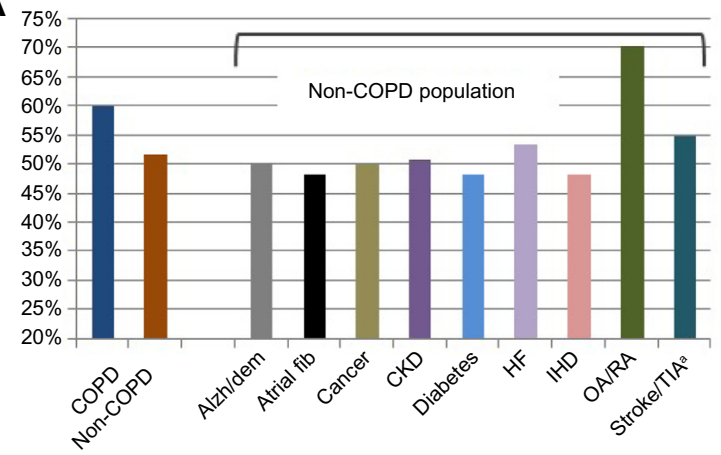

C

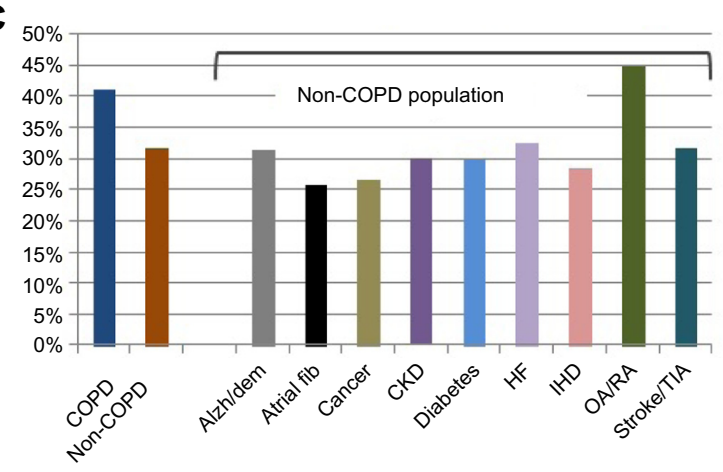

B

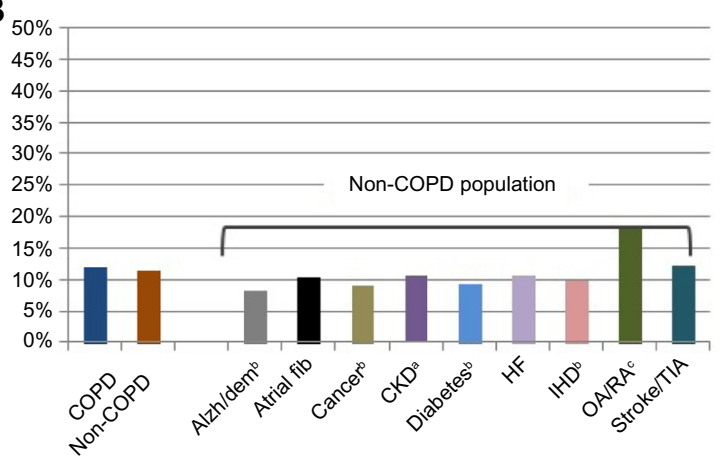

D

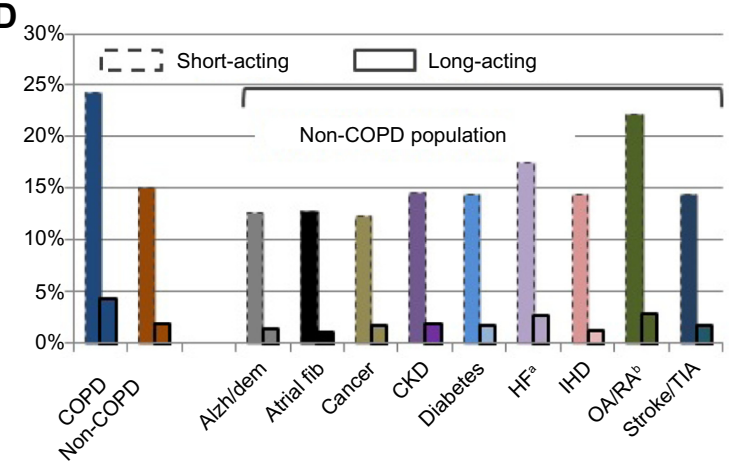

Figure I Evidence of chronic pain in patients with COPD compared to patients without COPD (non-COPD), overall and stratified by chronic disease.

Notes: (A) Any evidence of chronic pain (based on pain-related diagnoses, procedures, or prescription claims). ${ }^{\mathrm{a}} P<0.00 \mathrm{I} ; \boldsymbol{P}<0.000 \mathrm{I}$, all other comparisons. (B) Evidence of chronic pain based on pain-related procedures. ${ }^{a} P<0.05$; ${ }^{b} P<0.00$ I; ${ }^{c} P<0.000$ I. (C) Evidence of chronic pain based on pain-related medication. $P<0.000 \mathrm{I}$, all comparisons. (D) Evidence of chronic pain based on short-acting opioids and long-acting opioids. ${ }^{a} P<0.0$, long-acting; ${ }^{b} P<0.0$ I, short-acting; $P<0.000$ I, all others. Statistical comparisons are to COPD population.

Abbreviations: Alzh/dem, Alzheimer's, related disorders, or senile dementia; Atrial fib, atrial fibrillation; CKD, chronic kidney disease; COPD, chronic obstructive pulmonary disease; HF, heart failure; IHD, ischemic heart disease; OA/RA, osteo- and/or rheumatoid arthritis; TIA, transient ischemic attack.

utilization between the two groups. For example, patients with chronic pain averaged 10.3 more all-cause ambulatory visits during a 12-month period, but only 7.7 more painrelated ambulatory visits.

Table 6 provides a comparison of all-cause and painrelated direct medical costs between patients with and without evidence of chronic pain. The patients with chronic pain had on average total direct medical costs of $\$ 17,681$ during the 12-month follow-up period, as compared to $\$ 6,543$ for the patients without chronic pain $(P<0.0001$; effect size 0.43). Less than half of this difference was attributable to pain-related utilization $(\$ 3,925$ compared to $\$ 446, P<0.0001$; effect size 0.47 ). When the analysis is limited to only those who used services within each category (eg, mean inpatient cost among those who were hospitalized), there continues to be substantially increased costs among the chronic pain group that are not explained by pain-related services. For example, chronic pain patients with inpatient stays had mean all-cause inpatient costs that were $\$ 7,807$ greater than patients without chronic pain with inpatient stays $(\$ 22,814$ compared to $\$ 15,007)$, but inpatient stays that were pain-related were only $\$ 3,318$ greater. However, there was a larger effect size for the pain-related inpatient cost difference (effect size 0.43) compared to the all-cause inpatient difference (effect size 0.23 ). When the analysis is further restricted to the costs per event, persons with chronic pain still have consistently higher costs. The most meaningful mean cost per event differences were for all-cause outpatient events ( $\$ 70$ difference; effect size 0.19) and pain-related inpatient and prescription claims $(\$ 2,814$ difference, effect size 0.36 and $\$ 16$ difference, effect size 0.17 , respectively).

Figure 2 provides cost comparisons between those with and without chronic pain in the matched group, and for just patients with COPD. Among patients with COPD, the cost differences between those with and without chronic pain are even greater than those seen in the overall study population. On average, COPD patients with chronic pain had total direct medical costs over a 12 -month period of $\$ 24,261$, versus $\$ 10,390$ among COPD patients without chronic pain $(P<0.0001)$. Most of this difference is attributable to nonpain-related inpatient services. 
Table 4 Demographic characteristics, insurance types, and comorbidities associated with chronic pain utilization

\begin{tabular}{|c|c|c|c|c|c|}
\hline \multirow[t]{2}{*}{ Description } & \multicolumn{2}{|c|}{ Chronic pain } & \multicolumn{2}{|c|}{$\begin{array}{l}\text { No chronic pain } \\
\text { evident }\end{array}$} & \multirow{2}{*}{$\begin{array}{l}\text { Effect } \\
\text { size } \\
P^{a}\end{array}$} \\
\hline & $\mathbf{N}$ & $\%$ & $\mathbf{N}$ & $\%$ & \\
\hline Number of patients (\% of total) & 12,978 & $(54.4)$ & 10,878 & $(45.6)$ & \\
\hline Age categories & & & & & $\#$ \\
\hline $40-54$ years & 2,159 & $(16.6)$ & $\mathrm{I}, \mathrm{I} 26$ & $(10.4)$ & 0.18 \\
\hline $55-64$ years & 2,677 & $(20.6)$ & $\mathrm{I}, 732$ & $(15.9)$ & 0.12 \\
\hline $65-74$ years & 4,142 & $(31.9)$ & 4,087 & $(37.6)$ & 0.12 \\
\hline $75+$ years & 4,000 & $(30.8)$ & 3,933 & $(36.2)$ & 0.11 \\
\hline Age (years), mean (SD) & 67.6 & $(12.0)$ & 70.0 & $(11.0)^{*}$ & 0.21 \\
\hline Female & 8,328 & $(64.2)$ & 5,499 & $(50.6)^{*}$ & 0.28 \\
\hline Hispanic ethnicity & 4,750 & $(36.6)$ & 4,045 & $(37.2)$ & 0.01 \\
\hline Insurance coverage at matching event & & & & & $\#$ \\
\hline Commercial & 4,986 & (38.4) & 4,629 & $(42.6)$ & 0.09 \\
\hline Medicaid & $\mathrm{I}, 54 \mathrm{I}$ & $(11.9)$ & 454 & $(4.2)$ & 0.29 \\
\hline Medicare & 6,512 & $(50.2)$ & 5,863 & $(53.9)$ & 0.07 \\
\hline Type of encounter at matching event & & & & & \# \\
\hline Ambulatory visit & 11,839 & $(91.2)$ & 10,364 & $(95.3)$ & 0.16 \\
\hline ED visit & 720 & $(5.6)$ & 336 & (3.1) & 0.12 \\
\hline Discharge from inpatient stay & 419 & (3.2) & 178 & ( $(1.6)$ & 0.10 \\
\hline \multicolumn{6}{|l|}{ Chronic conditions $^{\mathrm{b}}$} \\
\hline AMI & 541 & $(4.2)$ & 466 & $(4.3)$ & 0.00 \\
\hline $\begin{array}{l}\text { Alzheimer's, related disorders, or } \\
\text { senile dementia }\end{array}$ & $\mathrm{I}, 086$ & $(8.4)$ & 914 & $(8.4)$ & 0.00 \\
\hline Atrial fibrillation & 1,410 & $(10.9)$ & $\mathrm{I}, 143$ & $(10.5)$ & 0.01 \\
\hline Cancers $^{c}$ & 1,483 & $(I 1.4)$ & $\mathrm{I}, 300$ & $(12.0)$ & 0.02 \\
\hline COPD & 4,754 & $(36.6)$ & 3,198 & $(29.4)^{*}$ & 0.15 \\
\hline CKD & 3,890 & $(30.0)$ & 3,123 & $(28.7)^{* * *}$ & 0.03 \\
\hline Diabetes & 4,692 & $(36.2)$ & 4,191 & $(38.5)^{* *}$ & 0.05 \\
\hline Heart failure & 2,323 & $(17.9)$ & I,557 & $(14.3)^{*}$ & 0.10 \\
\hline Ischemic heart disease & 3,287 & $(25.3)$ & 2,713 & $(24.9)$ & 0.01 \\
\hline OA/RA & 6,489 & $(50.0)$ & 2,413 & $(22.2)^{*}$ & 0.60 \\
\hline Stroke/transient ischemic attack & 1,550 & $(11.9)$ & $\mathrm{I}, 058$ & $(9.7)^{*}$ & 0.07 \\
\hline$>$ I of above chronic conditions & 8,132 & $(62.7)$ & 5,636 & $(51.8)^{*}$ & 0.22 \\
\hline Number of chronic conditions, mean (SD) & 2.4 & $(1.6)$ & 2.0 & $(1.3)^{*}$ & 0.27 \\
\hline
\end{tabular}

Notes: ${ }^{a} P$-values are for comparison to COPD: ${ }^{*} P<0.000$ I; ${ }^{* * P}<0.01$; $* * * P<0.05 ;{ }^{*} P<0.000$ I applies to the category overall, as well as each of the category components; bbased on one inpatient or two outpatient (ambulatory or ED visit) International Classification of Diseases, Ninth Revision, Clinical Modifiation diagnosis codes from Centers for Medicare and Medicaid Services Chronic Condition Warehouse; 'colorectal, endometrial, female breast, lung, or prostate.

Abbreviations: AMI, acute myocardial infarction; CKD, chronic kidney disease; COPD, chronic obstructive pulmonary disease; ED, emergency department; OA/RA, osteoand/or rheumatoid arthritis; SD, standard deviation.

\section{Discussion}

We found that COPD patients have substantially increased health care utilization and costs for pain-related services and medications as compared to similar persons with other chronic diseases. The COPD cohort had greater pain-related utilization than any other chronic condition except OA/ $\mathrm{RA}$, and even in that comparison, COPD had substantially more hospitalizations and inpatient cost. Risk factors for chronic pain include being female, age 40 to 64 years, having Medicaid coverage, and having certain comorbidities but especially COPD or OA/RA. Persons with chronic pain have much higher health care costs in all areas as compared to patients without chronic pain. Not all of this increase is directly attributable to pain utilization; therefore, the presence of chronic pain is a marker for individuals with high utilization in all service areas. When COPD patients are stratified by those with and without chronic pain, the cost differences are even further accentuated, especially for inpatient services.

These findings reveal new perspectives into COPD treatment and the relationship between health care utilization and chronic pain. The high prevalence of chronic pain among COPD patients was largely ignored until very recently. The current Consensus Report of the Global initiative for chronic Obstructive Lung Disease (GOLD), the most commonly cited international guidelines for 
Table 5 All-cause and pain-related health care utilization for patients with chronic pain and no chronic pain

\begin{tabular}{|c|c|c|c|c|c|}
\hline \multirow[t]{2}{*}{ Description } & \multicolumn{2}{|c|}{ Chronic pain } & \multicolumn{2}{|c|}{ No chronic pain ${ }^{\mathrm{a}}$} & \multirow{2}{*}{$\begin{array}{l}\text { Effect } \\
\text { size }\end{array}$} \\
\hline & $\mathbf{N}$ & $\%$ or SD & $\mathbf{N}$ & $\%$ or SD & \\
\hline Patients (\% of total) & 12,978 & $(54.4)$ & 10,878 & $(45.6)$ & \\
\hline \multicolumn{6}{|l|}{ All-cause utilization } \\
\hline \multicolumn{6}{|c|}{ Patients with any event during period by broad category (\%) } \\
\hline Outpatient services & 12,960 & (99.9) & 10,654 & $(97.9)$ & 0.19 \\
\hline Inpatient/institutional services & 3,863 & $(29.8)$ & 1,472 & $(13.5)$ & 0.40 \\
\hline Pharmacy claims & 12,736 & $(98.1)$ & 10,066 & $(92.5)$ & 0.27 \\
\hline \multicolumn{6}{|c|}{ Patients with any event during period by detailed category (\%) } \\
\hline Ambulatory visit & 12,938 & $(99.7)$ & 10,568 & $(97.2)$ & 0.20 \\
\hline ED visit & 4,456 & $(34.3)$ & I,87| & $(17.2)$ & 0.40 \\
\hline Inpatient stay & 3,594 & $(27.7)$ & $\mathrm{I}, 368$ & $(12.6)$ & 0.38 \\
\hline Institutional stay ${ }^{\mathrm{b}}$ & 717 & $(5.5)$ & 214 & $(2.0)$ & 0.19 \\
\hline Laboratory & 10,655 & $(82.1)$ & 8,292 & $(76.2)$ & 0.15 \\
\hline Pharmacy claims & 12,736 & $(98.1)$ & 10,066 & $(92.5)$ & 0.27 \\
\hline \multicolumn{6}{|c|}{ Mean (SD) events during period by detailed category } \\
\hline Ambulatory visit & 19.9 & $(15.9)$ & 9.7 & $(10.8)$ & 0.75 \\
\hline ED visit & 0.70 & $(1.58)$ & 0.25 & $(0.7 I)$ & 0.37 \\
\hline Inpatient stay & 0.41 & $(0.83)$ & 0.15 & $(0.44)$ & 0.39 \\
\hline Institutional stay ${ }^{\mathrm{b}}$ & 0.33 & (3.59) & 0.06 & $(0.89)$ & 0.10 \\
\hline Laboratory & 3.5 & $(4.06)$ & 2.4 & $(2.89)$ & 0.31 \\
\hline Pharmacy claims & 44.8 & $(36.1)$ & 25.8 & $(23.6)$ & 0.62 \\
\hline \multicolumn{6}{|l|}{ Pain-related utilization } \\
\hline \multicolumn{6}{|c|}{ Patients with any event during period by broad category (\%) } \\
\hline Outpatient services & 12,550 & $(96.7)$ & 6,650 & $(6 I . I)$ & 0.19 \\
\hline Inpatient/institutional services & 3,154 & $(24.3)$ & 858 & $(7.9)$ & 0.40 \\
\hline Pharmacy claims & $|1,04|$ & $(85.1)$ & 4,245 & $(39.0)$ & 0.27 \\
\hline \multicolumn{6}{|c|}{ Patients with any event during period by detailed category (\%) } \\
\hline Ambulatory visit & 12,340 & $(95.1)$ & 6,034 & $(55.5)$ & 0.20 \\
\hline ED visit & 3,249 & $(25.0)$ & 942 & $(8.7)$ & 0.40 \\
\hline Inpatient stay & 2,954 & $(22.8)$ & 826 & (7.6) & 0.38 \\
\hline Institutional stay ${ }^{\mathrm{b}}$ & 470 & (3.6) & 73 & $(0.7)$ & 0.19 \\
\hline Laboratory & 4,157 & $(32.0)$ & 1,326 & $(12.2)$ & 0.15 \\
\hline Pharmacy claims & $|I, 04|$ & $(85.1)$ & 4,245 & $(39.0)$ & 0.27 \\
\hline \multicolumn{6}{|l|}{ Mean (SD) events during period } \\
\hline Ambulatory visit & 8.9 & $(8.5)$ & 1.2 & $(1.6)$ & 0.06 \\
\hline ED visit & 0.43 & $(1.09)$ & 0.10 & $(0.36)$ & 0.15 \\
\hline Inpatient stay & 0.31 & $(0.67)$ & 0.08 & $(0.31)$ & 0.24 \\
\hline Institutional stay ${ }^{\mathrm{b}}$ & 0.14 & $(1.43)$ & 0.01 & $(0.20)$ & 0.03 \\
\hline Laboratory & 0.59 & $(1.20)$ & 0.15 & $(0.48)$ & 0.51 \\
\hline Pharmacy claims & 12.5 & $(15.6)$ & 1.91 & $(4.7)$ & 0.44 \\
\hline
\end{tabular}

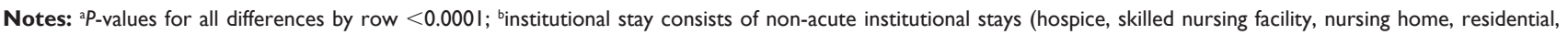
rehabilitation, overnight nonhospital dialysis, and other nonhospital stays).

Abbreviations: ED, emergency department; SD, standard deviation.

COPD management, does not mention pain either as a comorbidity or as an issue in clinical management. ${ }^{1}$ The current joint COPD clinical management guideline of the American College of Physicians, American College of Chest Physicians, American Thoracic Society, and European Respiratory Society does not mention pain, even though it does stress the importance of attention to comorbidities and taking an integrated approach for optimal clinical management. ${ }^{28}$ The current American Thoracic Society report on the integrated care of COPD patients does not mention pain in any context. ${ }^{29}$ The results of our analysis suggest that attention to the very high burden of pain among COPD patients is a major opportunity to improve the clinical management of COPD patients.

Several analyses of health care costs in COPD have shown that COPD is among the most expensive chronic illnesses, and that hospitalizations for COPD exacerbations are a major contributor to the increased costs. ${ }^{30}$ As new treatments for COPD that reduce the risk of exacerbations of COPD have become available, recognition that aggressive 
Table 6 Direct medical costs over 12-month period: all-cause and pain-related in patients with chronic pain and no chronic pain

\begin{tabular}{|c|c|c|c|c|c|}
\hline \multirow[t]{2}{*}{ Description } & \multicolumn{2}{|c|}{ Chronic pain } & \multicolumn{2}{|c|}{ No chronic pain } & \multirow{2}{*}{$\begin{array}{l}\text { Effect } \\
\text { size }^{a}\end{array}$} \\
\hline & $\mathbf{N}$ & $\%$ or SD & $\overline{\mathbf{N}}$ & $\%$ or SD & \\
\hline Patients (\% of total) & 12,978 & $(54.4)$ & 10,878 & $(45.6)$ & \\
\hline \multicolumn{6}{|l|}{ All-cause utilization cost } \\
\hline \multicolumn{6}{|l|}{ Overall mean (SD) } \\
\hline Outpatient services & 8,456 & $(16,796)$ & 3,298 & $(7,972)$ & 0.39 \\
\hline Inpatient/institutional services & 6,791 & $(24,833)$ & 2,031 & $(10,243)$ & 0.25 \\
\hline Pharmacy & 2,434 & $(3,904)$ & 1,214 & $(1,880)$ & 0.40 \\
\hline Total & $17,68 \mid$ & $(33,416)$ & 6,543 & $(14,227)$ & 0.43 \\
\hline \multicolumn{6}{|c|}{ Mean cost (SD) per patient with utilization within category } \\
\hline Outpatient services & $8,468^{\circ}$ & $(16,805)$ & 3,368 & $(8,04 I)$ & 0.39 \\
\hline Inpatient/institutional services & 22,814 & $(41,309)$ & 15,007 & $(24,101)$ & 0.23 \\
\hline Pharmacy & 2,480 & $(3,926)$ & 1,312 & $(1,921)$ & 0.38 \\
\hline Total & $|7,68|$ & $(33,416)$ & 6,607 & $(|4,28|)$ & 0.43 \\
\hline \multicolumn{6}{|c|}{ Mean cost $(\mathrm{SD})$ per event for patients with utilization within category } \\
\hline Per outpatient event & 279 & $(409)$ & 209 & $(310)$ & 0.19 \\
\hline Per inpatient/institutional stay & 13,544 & $(23,210)$ & 11,612 & $(19,065)$ & $0.09^{\mathrm{b}}$ \\
\hline Per prescription & 55 & (99) & 49 & $(74)$ & 0.07 \\
\hline \multicolumn{6}{|l|}{ Pain-related utilization costs } \\
\hline \multicolumn{6}{|l|}{ Overall mean (SD) } \\
\hline Outpatient services & 1,843 & $(7,5 \mid 2)$ & 224 & (777) & 0.30 \\
\hline Inpatient/institutional services & 1,336 & $(6,182)$ & 125 & $(1,674)$ & 0.27 \\
\hline Pharmacy & 746 & $(2,075)$ & 97 & $(511)$ & 0.43 \\
\hline Total & 3,925 & $(10,317)$ & 446 & $(1,947)$ & 0.47 \\
\hline \multicolumn{6}{|c|}{ Mean cost (SD) per patient with utilization within category } \\
\hline Outpatient services & 1,906 & $(7,631)$ & 367 & $(967)$ & 0.28 \\
\hline Inpatient/institutional services & 5,499 & $(11,593)$ & 1,590 & $(5,763)$ & 0.43 \\
\hline Pharmacy & 877 & $(2,225)$ & 247 & $(795)$ & 0.38 \\
\hline Total & 3,926 & $(10,318)$ & 608 & $(2,25 I)$ & 0.44 \\
\hline \multicolumn{6}{|c|}{ Mean cost (SD) per event for patients with utilization within category } \\
\hline Per outpatient event & 162 & $(380)$ & 140 & (395) & 0.06 \\
\hline Per inpatient/institutional stay & 4,209 & $(9,422)$ & 1,395 & $(5,5 \mid 0)$ & 0.36 \\
\hline Per prescription & 46 & $(118)$ & 30 & $(60)$ & 0.17 \\
\hline
\end{tabular}

Note: ${ }^{a}$-value $<0.000$ I for all comparisons by row, except ${ }^{b} P=0.002$.

Abbreviation: SD, standard deviation.

COPD treatment is not only clinically beneficial but highly cost-effective has contributed to an evolution in the treatment approach for COPD from a palliative philosophy to one emphasizing health maintenance and preventive care. ${ }^{1,28}$ Our data suggest that improved pain management in COPD has the potential to help many patients and be costeffective if it can reduce utilization in other areas, especially hospitalizations.

This study has limitations in its design that should be considered. Although it is a population-based study, it is likely that the demographic and utilization characteristics in this cohort are different than those of other COPD cohorts, creating the possibility of selection biases. We did find that Medicaid patients, who are younger and likely to have Medicaid because they are disabled, had substantially higher pain-related utilization. Populations with a different mix of demographics and types of health insurance may have different results. There is undoubtedly some degree of confounding by age and by chronic condition that biases the pain utilization estimates, especially in the comparison of the patients with COPD to those without COPD by specific chronic conditions. However, in our previous epidemiologic analysis of pain utilization, ${ }^{18}$ multivariate adjustment including patient age and comorbidities did not substantially change the effect estimates between COPD and pain. Another limitation is that symptom management is often poor among patients with COPD and symptoms such as pain are often unrecognized and untreated, which creates the possibility of misclassification and measurement errors.

There are now several studies with a variety of research designs but consistent in the conclusion that COPD patients have a high prevalence of chronic pain. ${ }^{31}$ Our study complements these by additionally offering insights into the economic burden associated with chronic pain as well as new 


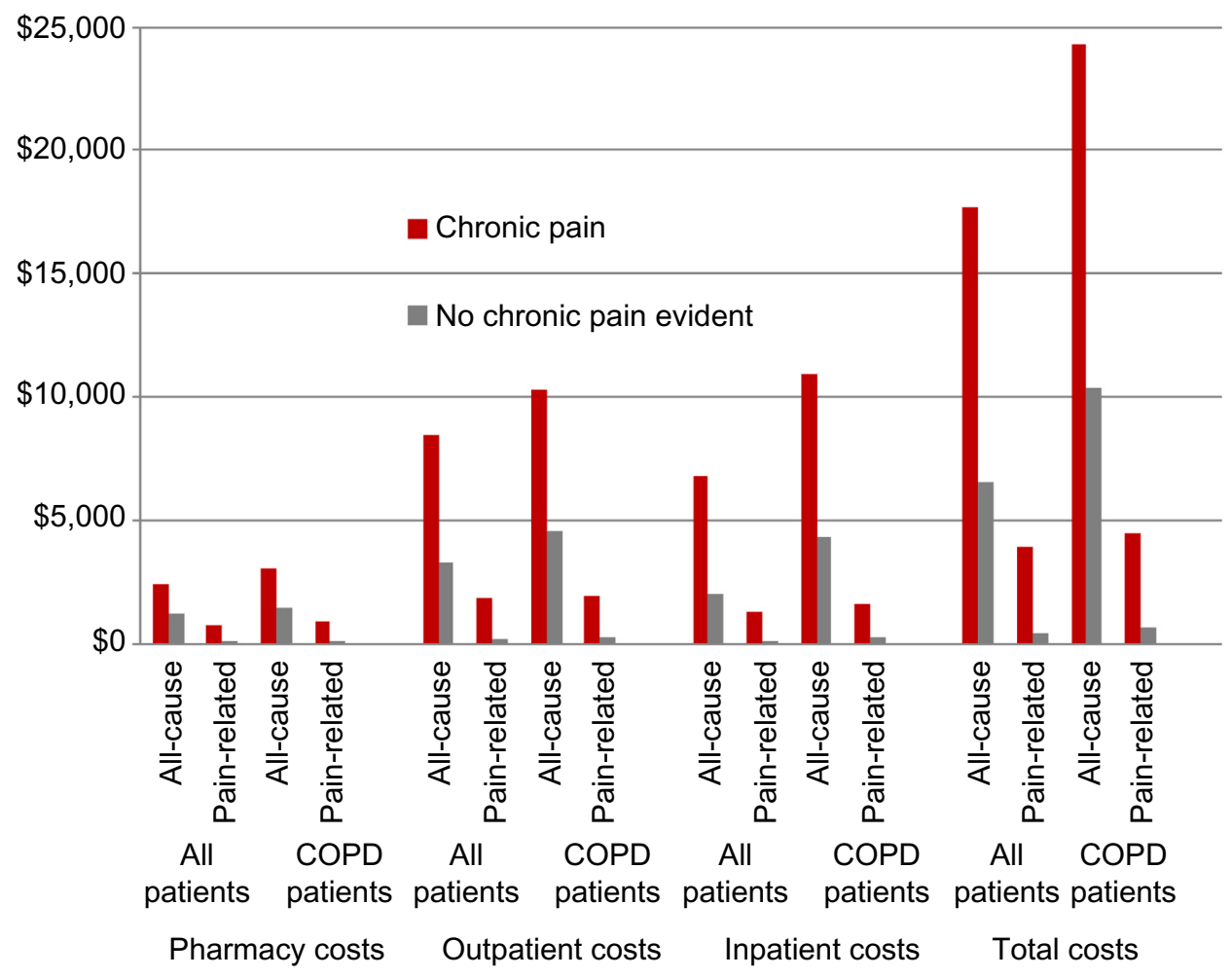

Figure 2 Direct all-cause and pain-related medical cost comparisons between those with and without chronic pain among all patients and patients with COPD. Note: $P$-value $<0.000$ I for all comparisons.

Abbreviation: COPD, chronic obstructive pulmonary disease.

insights into the factors that result in the increased utilization of pain- and non-pain-related health care utilization.

\section{Disclosure}

Grant funding for the investigator initiated study summarized in this manuscript was provided by Endo Pharmaceuticals, Malvern, PA (USA). The authors report no other conflicts of interest in this work.

\section{References}

1. Global initiative for chronic Obstructive Lung Disease (GOLD). Global Strategy for the Diagnosis, Management and Prevention of COPD. GOLD; 2011. Available from: http://www.goldcopd.org/uploads/users/ files/GOLD_Report_2011_Feb21.pdf. Accessed January 5, 2012.

2. Van Wave TW, Scutchfield FD, Honoré PA. Recent advances in public health systems research in the United States. Annu Rev Public Health. 2010;31:283-295.

3. National Heart, Lung, and Blood Institute. Morbidity and Mortality: 2012 Chart Book on Cardiovascular, Lung, and Blood Diseases. National Heart, Lung, and Blood Institute; 2012. Available from: http://www.nhlbi.nih.gov/ files/docs/research/2012_ChartBook.pdf. Accessed February 27, 2015.

4. Centers for Disease Control and Prevention (CDC). Deaths from chronic obstructive pulmonary disease - United States, 2000-2005. MMWR Morb Mortal Wkly Rep. 2008;57(45):1229-1232.

5. Mannino DM, Homa DM, Akinbami LJ, Ford ES, Redd SC. Chronic obstructive pulmonary disease surveillance - United States, 1971-2000. MMWR Surveill Summ. 2002;51(6):1-16.
6. Trupin L, Earnest G, San Pedro M, et al. The occupational burden of chronic obstructive pulmonary disease. Eur Respir J. 2003;22(3): 462-469.

7. Eisner MD, Yelin EH, Trupin L, Blanc PD. The influence of chronic respiratory conditions on health status and work disability. Am J Public Health. 2002;92(9):1506-1513.

8. Blanc PD, Menezes AM, Plana E, et al. Occupational exposures and COPD: an ecological analysis of international data. Eur Respir J. 2009;33(2):298-304.

9. Blanchette CM, Dalal AA, Mapel D. Changes in COPD demographics and costs over 20 years. J Med Econ. 2012;15(6):1176-1182.

10. Machlin S, Chowdhury S. Expenses and Characteristics of Physician Visits in Different Ambulatory Care Settings, 2008. Statistical Brief \#318. Rockville, MD: Agency for Healthcare Research and Quality; 2011. Available from: http://www.meps.ahrq.gov/mepsweb/data_files/ publications/st318/stat318.pdf. Accessed January 5, 2012.

11. Soni A. Top 10 Most Costly Conditions among Men and Women, 2008: Estimates for the U.S. Civilian Noninstitutionalized Adult Population, Age 18 and Older [webpage on the Internet]. Statistical Brief \#331. Rockville, MD: Agency for Healthcare Research and Quality; 2011. Available from: http://www.meps.ahrq.gov/mepsweb/data_files/ publications/st331/stat331.shtml. Accessed January 5, 2012.

12. Centers for Disease Control and Prevention (CDC). Prevalence and most common causes of disability among adults - United States, 2005. MMWR Morb Mortal Wkly Rep. 2009;58(16):421-426.

13. Centers for Disease Control and Prevention (CDC). Smokingattributable mortality, years of potential life lost, and productivity losses - United States, 2000-2004. MMWR Morb Mortal Wkly Rep. 2008;57(45):1226-1228.

14. Wouters EF. Economic analysis of the Confronting COPD survey: an overview of results. Respir Med. 2003;97 Suppl C:S3-S14. 
15. Mapel DW, Dedrick D, Davis K. Trends and cardiovascular co-morbidities of COPD patients in the Veterans Administration Medical System, 1991-1999. COPD. 2005;2(1):35-41.

16. Mapel DW, Hurley JS, Frost FJ, Petersen HV, Picchi MA, Coultas DB. Health care utilization in chronic obstructive pulmonary disease. A case-control study in a health maintenance organization. Arch Intern Med. 2000;160(17):2653-2658.

17. Schneider KM, O’Donnell BE, Dean D. Prevalence of multiple chronic conditions in the United States' Medicare population. Health Qual Life Outcomes. 2009;7:82.

18. Roberts MH, Mapel DW, Hartry A, Von Worley A, Thomson H. Chronic pain and pain medication use in chronic obstructive pulmonary disease. A cross-sectional study. Ann Am Thorac Soc. 2013;10(4): 290-298.

19. Bentsen SB, Rustøen T, Miaskowski C. Prevalence and characteristics of pain in patients with chronic obstructive pulmonary disease compared to the Norwegian general population. J Pain. 2011;12(5): 539-545.

20. HajGhanbari B, Holsti L, Road JD, Darlene Reid W. Pain in people with chronic obstructive pulmonary disease (COPD). Respir Med. 2012;106(7):998-1005.

21. Arne M, Lundin F, Boman G, Janson C, Janson S, Emtner M. Factors associated with good self-rated health and quality of life in subjects with self-reported COPD. Int J Chron Obstruct Pulmon Dis. 2011;6: 511-519.

22. Johansson EL, Ternesten-Hasséus E, Olsén MF, Millqvist E. Respiratory movement and pain thresholds in airway environmental sensitivity, asthma and COPD. Respir Med. 2012;106(7):1006-1013.

23. DuGoff EH, Canudas-Romo V, Buttorff C, Leff B, Anderson GF. Multiple chronic conditions and life expectancy: a life table analysis. Med Care. 2014;52(8):688-694.
24. Elixhauser A, Steiner C, Harris DR, Coffey RM. Comorbidity measures for use with administrative data. Med Care. 1998;36(1):8-27.

25. Cohen J. Statistical power analysis. Curr Dir Psychol Sci. 1992;1: 98-101.

26. Samet JM, Schrag SD, Howard CA, Key CR, Pathak DR. Respiratory disease in a New Mexico population sample of Hispanic and nonHispanic whites. Am Rev Respir Dis. 1982;125:152-157.

27. Samet JM, Coultas DB, Howard CA, Skipper BJ. Respiratory diseases and cigarette smoking in a Hispanic population in New Mexico. Am Rev Respir Dis. 1988;137(4):815-819.

28. Qaseem A, Wilt TJ, Weinberger SE, et al; American College of Physicians; American College of Chest Physicians; American Thoracic Society; European Respiratory Society. Diagnosis and management of stable chronic obstructive pulmonary disease: a clinical practice guideline update from the American College of Physicians, American College of Chest Physicians, American Thoracic Society, and European Respiratory Society. Ann Intern Med. 2011;155(3):179-191.

29. Nici L, ZuWallack R; American Thoracic Society Subcommittee on Integrated Care of the COPD Patient. An official American Thoracic Society workshop report: the Integrated Care of The COPD Patient. Proc Am Thorac Soc. 2012;9(1):9-18.

30. Mapel DW, Roberts MH. New clinical insights into chronic obstructive pulmonary disease and their implications for pharmacoeconomic analyses. Pharmacoeconomics. 2012;30(10):869-885.

31. van Dam van Isselt EF, Groenewegen-Sipkema KH, Spruit-van Eijk M, et al. Pain in patients with COPD: a systematic review and meta-analysis. BMJ Open. 2014;4(9):e005898.
ClinicoEconomics and Outcomes Research

\section{Publish your work in this journal}

ClinicoEconomics \& Outcomes Research is an international, peerreviewed open-access journal focusing on Health Technology Assessment, Pharmacoeconomics and Outcomes Research in the areas of diagnosis, medical devices, and clinical, surgical and pharmacological intervention. The economic impact of health policy and health systems

\section{Dovepress}

organization also constitute important areas of coverage. The manuscript management system is completely online and includes a very quick and fair peer-review system, which is all easy to use. Visit http://www.dovepress.com/testimonials.php to read real quotes from published authors. 